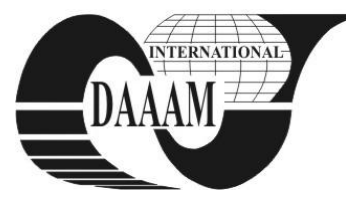

Annals of DAAAM for 2011 \& Proceedings of the 22nd International DAAAM Symposium, Volume 22, No. 1, ISSN 1726-9679 ISBN 978-3-901509-83-4, Editor B. Katalinic, Published by DAAAM International, Vienna, Austria, EU, 2011 Make Harmony between Technology and Nature, and Your Mind will Fly Free as a Bird

\title{
APPLICATION OF SIMULATION METHODS FOR ESTIMATION OF RELIABILITY OF UNDERWATER PIPELINE TRACKS IN FROZEN SEAS
}

\author{
BEKKER, A[lexander] T[evievich]; RUSAKOV, D[mitrii] S[ergeevich] \& SABODASH, O[lga] A[lekseevna]
}

\begin{abstract}
Drifting hummocks are the major hazard to exploitation of underwater pipelines in freezing seas because such hummocks may contact the sea bottom, as well as pipelines, during their movement in shallow waters.

In this paper, the authors have considered the problems of track choice for an underwater pipeline for offshore Sakhalin. For such purpose, there was applied a probabilistic approach to calculation of spatial position of the underwater pipeline track taking into account of bottom topography.

Key words: pipeline, hummocks, simulation, reliability, sea bottom
\end{abstract}

\section{INTRODUCTION}

We should take into consideration action of the ice features, when designing or constructing the underwater pipelines or other structures on the offshore.

The drifting hummocks are the main hazard to underwater pipelines in the freezing seas. They penetrate in the sea bottom in shallow waters and can to damage the pipelines during movement. This fact is confirmed by statistical data of failure of existing pipelines in Arctic seas (C-CORE, 2002). At the present time, burying of pipelines into bottom soil is the main and the most effective measure of pipeline protection from ice impacts.

It is generally known that ice conditions have spatialtemporal variability and inhomogeneity (SNiP, 1989). Besides, the sea bottom topography and soil properties are the stochastic properties.

The purpose of this study is to develop the methodology of choice of the pipeline track basing on base of reliability theory. The probabilistic simulation model of hummocks impact on sea bottom was developed taking into account the numerical/statistic simulation methods. The calculations of optimum variants of spatial track of the underwater pipeline at Piltun-Astokhskoe oil\&gas field on Sakhalin offshore were made.

\section{SIMULATION MODEL}

The criterion of optimization of a spatial distribution of pipeline track is looking that (Surkov, 2000):

$$
P_{d} \geq P_{n}
$$

where $P_{d}$ is a design level of reliability of the pipeline; $P_{n}$ is a target reliability level.

The probability of lack of contact of the pipeline with hummock for some time period can be accepted as a design level of reliability and calculated as (Surkov, 2000):

$$
P_{d}=\int_{0}^{h_{d}} p(h) d h,
$$

where $h_{d}$ is a pipeline burial depth in sea bottom; $p(h)$ is distribution function of probability density of penetration depths $h$ of drifting hummocks in sea bottom.

Hence, for optimization calculations of a spatial track of the underwater pipeline it is necessary to determine:

-distribution function of frequency penetration of hummocks in sea bottom $p(h)$;

- target reliability level of pipeline.

It is possible to solve the equation (2) only on base of a simulation modelling. Main elements of the simulation model of "ice-bottom-pipe" are:

- probabilistic characteristics of the parameters of ice regime and drifting ice features;

- bathymetry of sea bottom along pipeline track;

- bottom soil properties.

Statistical modeling of probabilistic parameters of hummocks (taking into account with their actual probability functions of distribution) was carried out by Monte-Carlo method in according to author's specified algorithm and a computer program. Modeling of the sea bottom geometry and topography was made on the base of GIS technique. This simulation model was considered in detail by (Bekker et al., 2006). The presented paper is the original addition to existing authors'model in part of reliability estimation of pipeline track.

\section{CALCULATION EXAMPLE}

The procedure of probabilistic calculation for the optimum track of the underwater pipeline was applied by the PiltunAstokhskoe oil\&gas field.

The pipeline track has been calculated on the base of technology of GIS, that is allows finding at the given reliability level $P_{n}$ the shortest spatial distance between points of a burial depth of the pipeline in sea bottom.

At the first stage of calculations, we assume that the penetration depth of hummock, $h$, is the random value with Gaussian distribution function. This parameter was calculated on the base of simulation model of the hummock's penetration into soil according to deterministic model of interaction, studied in detail by (Bekker et al., 2006).

At the second stage of calculations, we describe the computer model of the sea bottom topography. It was represented by grid of depth isobathic curves with pitch distance of two meters to generation of geospatial data. For the whole water area, plans of depths and horizontal distances were dimensioned like 1:500.

Then we made simulation modeling of the physical process of hummocks' penetration into sea bottom in accordance with special algorithm discussed in the study (Bekker et al., 2006) and program of statistical modeling of hummocks' parameters by Monte-Carlo method. At each stage of modelling for corresponding depth of the sea bottom we randomly changed the following parameters of the hummocks: keel width $B(I)$, 
keel depth $H_{K}(J)$, angle attack of keel $\varepsilon(K)$, drift velocity $V(P)$, sail height $H_{s}(L)$. Number of members of generated series $N$ is equal 10000 values. At each stage of modeling the angle of bottom slope $\alpha$ and soil properties were accepted a constant (nonrandom value).

For each random combination of parameters of hummocks and sea bottom characteristics the distribution function of probability density of penetration depths of hummocks into soil $p(h)$ was received.

During simulation modelling of hummocks' drift velocity $V(P)$ all directions and angles between a hummocks and pipeline track (including from coast) were considered. These parameters have the different probabilities, that taken into account at calculations of $p(h)$.

The calculation of a pipeline burial depth, $h_{d}$, was made by expression (2) at the different values of target reliability levels $P_{n}$ : from 0.99 to 0.999999 . Figure 1 shows the calculation results of pipeline burial depth at the different water depths and target reliability levels.

On Figure 3 we illustrate the scheme of sea bottom with buried pipeline on Piltun-Astokhskoe field in according to GIS technologies at target reliability level $P_{n}=0.9999$. On this figure the "Molikpaq" platform (PA-A) on the 30-m depth on and Piltun-Astokhskaya platform (PA-B) on the 28-m depth is shown. These platforms were installed on the deposit in 1998 and 2005 (Vershinin, 2008). The pipeline track begins from each platform and has a length from 15 to 25 kilometers away of the sea coast. The calculation results are: the minimum value of pipeline burial depth is equal $0.92 \mathrm{~m}$, average value is equal $1.08 \mathrm{~m}$, and maximum value is equal $1.22 \mathrm{~m}$.

These results were received by the reliability theory analysis only for ice actions. Nevertheless, Sakhalin offshore is located in zone of intensive seismic activity and also is exposed by sufficient action of sediments. Figure 3 shows the abrasion and accumulation zones of sediments, which are necessary to consider at choice of pipeline track. That is why the initial results of calculations of burial depth of pipeline demand more accurate definition taking into consideration the other actions, besides ice.

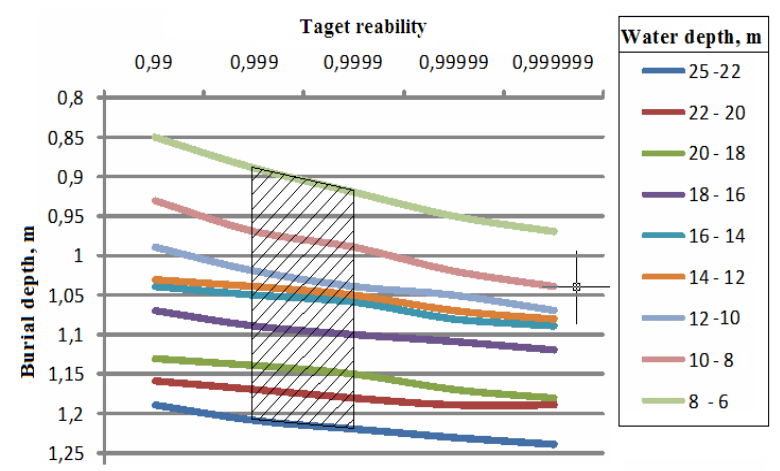

Fig. 1. Burial depth of underwater pipeline versus target reliability level at the various water depths.

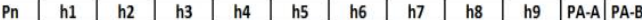

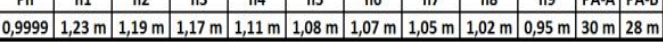

Offshore line

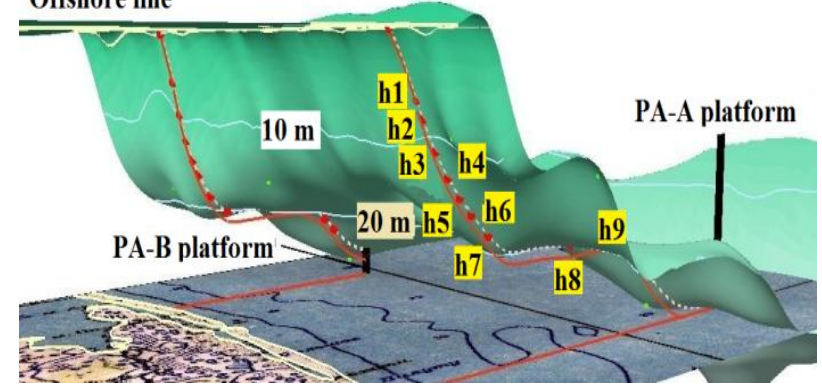

Fig. 2. The map of pipeline burial depth on Piltun-Astokhskoe field on the base of GIS at target reliability level $P_{n}=0.9999$ (scale 1:500).

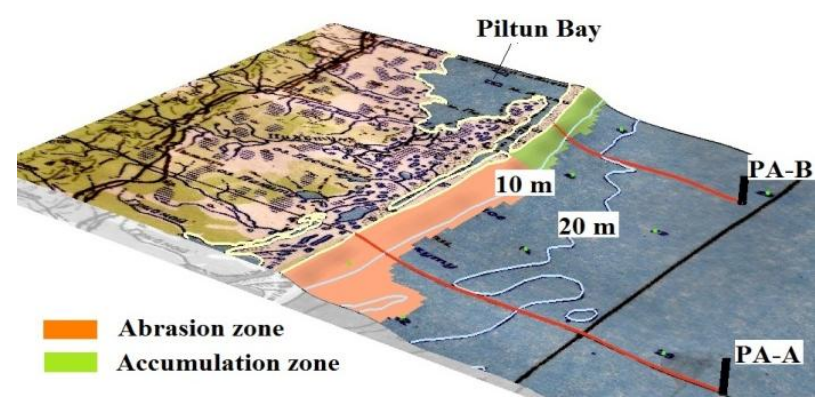

Fig. 3. The plane view of pipeline track on Piltun-Astokhskoe field by GIS at target reliability level $P_{n}=0.9999$ (scale 1:500).

\section{CONCLUSIONS}

1. The probabilistic simulation technique of choice of optimum spatial track of underwater pipeline for Piltun-Astokhskoe oil\&gas field on Sakhalin offshore was developed.

2.In according to proposed procedure we received the following results: minimum value of pipeline burial depth is equal $0.92 \mathrm{~m}$, average value is equal $1.08 \mathrm{~m}$, and maximum value is equal $1.22 \mathrm{~m}$ at target reliability level $P_{n}=0.9999$.

3. The future investigations must include the development of probabilistic models of sediment and seismic activity at the designing of underwater pipeline track on Sakhalin offshore zone.

\section{REFERENCES}

Bekker, A. \& Sabodash, O. (2006). The Probabilistic Approach to Modelling of an Optimal Underwater Pipeline Rout under Impact of Hummocks. Proceedings of the 18th International. Symposium on Ice, 28 August - 1 September, Sapporo, Japan, ISBN 978-0-9810446-0-6, Saeki, H. (Ed.), Vol.1, pp. 325334, IAHR, Ice Research\&Engineering, Madrid

SNiP 2.06.07-87 (1987). Embankment Walls, Navigable Sluices, Fish-Passing and Fish-Defended Constructions, Gosstroy of USSR, Moscow, Russia (in Russian)

Surkov, G. (2000). Choosing Optimum Subsea Pipeline Burial Profile on Northeast Sakhalin Shelf. Proceedings of $2^{\text {nd }}$ Ice Scour\&Arctic Marine Pipelines Workshop, $15^{\text {th }}$ International Symposium on Okhotsk Sea\&Sea Ice, February 7-9, Mombetsu, Japan, pp. 207-217, Okhotsk Sea \& Cold Ocean Research Association (OSCORA), Mombetsu

Vershinin, S.; Truskov, P. \& Liferov, P. (2008). Ice Action on Seabed and Subsea Structures, Russkaya Kniga, Moscow

*** (2002) Ice Hazard\&Integrity Analysis for Sakhalin II Project Offshore Pipelines: Probabilistic Assessment\&Recommended Burial Depths, C-CORE Report $R-01-19-631-15$ 